\title{
Analysis of Geotechnical and Consolidation Characteristics: A Case Study of UET, Kala Shah Kaku Campus, Lahore, Pakistan
}

\author{
Sadia Sohail, N. Aadil, and M. S. Khan
}

\begin{abstract}
Assessing the geotechnical parameters helps in improving the soil settlement which usually causes damage to the civil structure. In this study, geotechnical investigations at UET, Kala Shah Kaku Campas (KSK), Lahore site are carried out for undisturbed samples at depths of $2 \mathrm{ft}, 3 \mathrm{ft}, 4 \mathrm{ft}$ and $5 \mathrm{ft}$. in orderto soil classification and assess the consolidation parameters on undisturbed and disturbed/remolded samples.

Results indicate that the soil grade from top layer of silty clay (CL-ML) to lean clay (CL) from $3 \mathrm{ft}$ to $5 \mathrm{ft}$ depth. The natural moisture content is very low and the plastic limit varies from 20 to 23 . The liquidity index shows that the soil of the study area is of semisolid or solid state. Void ratio varies from 0.70 to 0.96 for undisturbed samples and 0.60 to 0.90 for disturbed samples. Specific gravity and Bulk density range from 2.68 to 2.69 and 14.0 to $16.0 \mathrm{kN} / \mathrm{m}^{2}$ respectively. The over consolidation ratio (OCR) values up to $5 \mathrm{ft}$ depth are in the range of 4.1 to 7.0 .

It is found that compressibility characteristics decrease with depth. The coefficient of primary and secondary consolidation decreases with increase in applied pressure and tends to be more or less constant at high pressures.
\end{abstract}

Index Terms-Compressibility, Consolidation Parameters, Geotechnical Parameters, Soil Classification, Soil Settlement

\section{INTRODUCTION}

Settlement of the subsoil causes damage to the structures due to stability problems which needs to address before planning any engineering project [1]. Consolidation characteristics of a soil depend mainly on the clay contents and plasticity index. Settlement potential of soil increases with increase of these values. However, higher values of these characteristics are not desirable for use of such soil under foundations and roads etc. Efforts are made to reduce the settlement potential of such soils. The purpose of this research work was to determine the effect of sand mixing on the consolidation characteristics of Kala Shah Kaku clay.

The construction and development of new engineering structures; industrial buildings, roads, bridges, and office blocks together is being planned at KSK, Lahore (Fig. 1) as an extension programme of UET and other academic institutions. In this study, geotechnical investigations are carried out for undisturbed samples to determine consolidation characteristics of cohesive soil present in the

Manuscript received August 5, 2012; revised September 12, 2012.

The authors are with the Department of Gelogical Engineering, University of Engineering \& Technology, Lahore-54890, Pakistan. study area. Soil classification and consolidation assessment tests were performed on undisturbed and disturbed/remolded samples in order to observe the effect of depth on consolidation characteristics.

\section{Methodology}

Undisturbed block samples at $2 \mathrm{ft}, 3 \mathrm{ft}$, $4 \mathrm{ft}$ and $5 \mathrm{ft}$ depths and sand for mixing with the clay were collected, sealed, marked and stored until the time of testing from the location area as shown in Fig. 1. Basic soil classification tests and Oedometer test were performed on undisturbed and disturbed/remolded samples. All tests were performed according to ASTM standards [2].

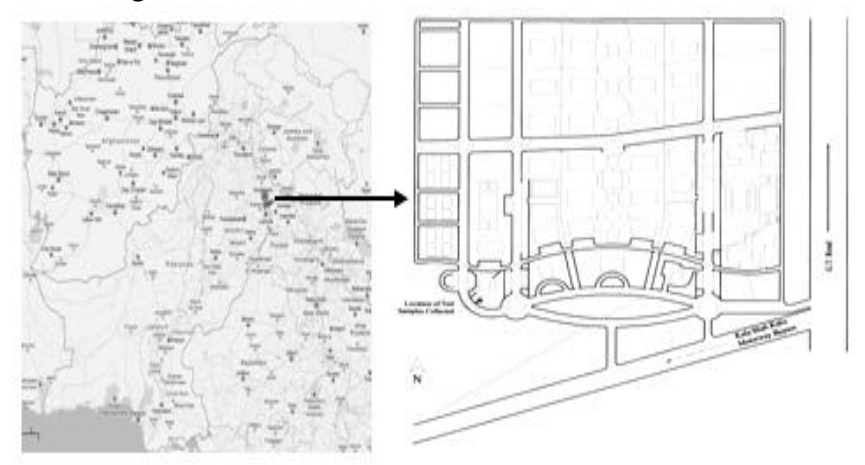

Fig. 1. Location map of study area

\section{RESUlTS}

The determination of index properties is an important adjunct to consolidation test. Tests were performed to measure Specific Gravity (Gs), Atterberg limits, Particle size distribution and Hydrometer test. The determined parameters as shown in Table I will be used for both soil classification and assessing the consolidation characteristics. Top layer is cohesive soil consisting of silty clay/silt/sandy silt (CL-ML/M/ML) and its thickness varies from about three feet $(3 \mathrm{ft})$ to twenty feet $(20 \mathrm{ft})$. The upper stratum is followed by non-cohesive soil comprising of sand having variable amount of silt. The bottom stratum extends to the maximum investigated depth of $50 \mathrm{ft}$ [3].

Based on Atterberg limits as plotted on the Casagrande's plasticity chart (Fig. 2), the data points above Casagrande's A-line and the soil in hatched zone is classified as CL-ML [4]. 
Table I: Soil Classification Parameters with Basic Soil Properties. LL, PL, PI, and Li Indicate Liquid Limit, Plastic Limit, Plasticity Index

\begin{tabular}{|c|c|c|c|c|c|c|c|c|c|c|c|c|c|c|}
\hline \multirow[b]{2}{*}{ Sample } & \multirow{2}{*}{$\begin{array}{c}\text { Depth } \\
\text { [ft } \\
(\mathbf{m})]\end{array}$} & \multirow{2}{*}{$\begin{array}{c}\text { Natural } \\
\text { M.C } \\
(\%)\end{array}$} & \multirow{2}{*}{$\begin{array}{c}\text { Sp. } \\
\text { Gravity } \\
\text { ( Gs) }\end{array}$} & \multicolumn{3}{|c|}{ Grain Size Analysis } & \multicolumn{4}{|c|}{ Atterberg Limits } & \multirow[b]{2}{*}{$\begin{array}{c}\text { Soil } \\
\text { C'fication }\end{array}$} & \multirow{2}{*}{$\begin{array}{l}\text { Initial } \\
\text { Void } \\
\text { Ratio }\end{array}$} & \multirow{2}{*}{$\begin{array}{c}\text { Initial } \\
\text { Bulk } \\
\text { Density }\end{array}$} & \multirow{2}{*}{$\begin{array}{c}\text { Initial } \\
\text { Degree of } \\
\text { Saturation }\end{array}$} \\
\hline & & & & $\begin{array}{l}\text { Gravel } \\
(\%)\end{array}$ & $\begin{array}{l}\text { Sand } \\
(\%)\end{array}$ & $\begin{array}{l}\text { Silt \& } \\
\text { Clay } \\
(\%)\end{array}$ & LL (\%) & $\begin{array}{l}\text { PL } \\
(\%)\end{array}$ & $\begin{array}{l}\text { PI } \\
(\%)\end{array}$ & $\begin{array}{l}\text { LI } \\
(\%)\end{array}$ & & & & \\
\hline 1 & $2(0.6)$ & 1.01 & 2.69 & 0 & 3 & 97 & 27 & 20 & 7 & -2.7 & CL-ML & 0.91 & 14 & 3.02 \\
\hline 2 & $3(0.9)$ & 1.28 & 2.68 & 0 & 5 & 95 & 28 & 22 & 6 & -3.5 & CL-ML & 0.71 & 15.6 & 4.83 \\
\hline 3 & $4(1.2)$ & 1.4 & 2.69 & 0 & 7 & 93 & 34 & 23 & 11 & -1.9 & CL & 0.76 & 15.2 & 4.93 \\
\hline 4 & $5(1.5)$ & 16 & 2.69 & 1 & 5 & 94 & 29 & 21 & 8 & -0.6 & CL & 0.94 & 15.8 & 46.12 \\
\hline
\end{tabular}

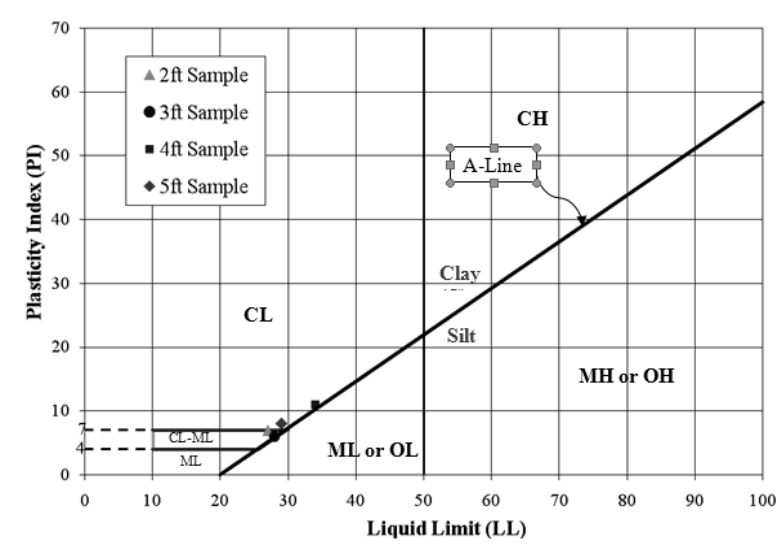

Fig. 2. Atterberg Limits on casagrande plasticity chart

\section{DISCUSSION}

The results of consolidation tests are plotted from Fig. 4 to 15 which is discussed below.
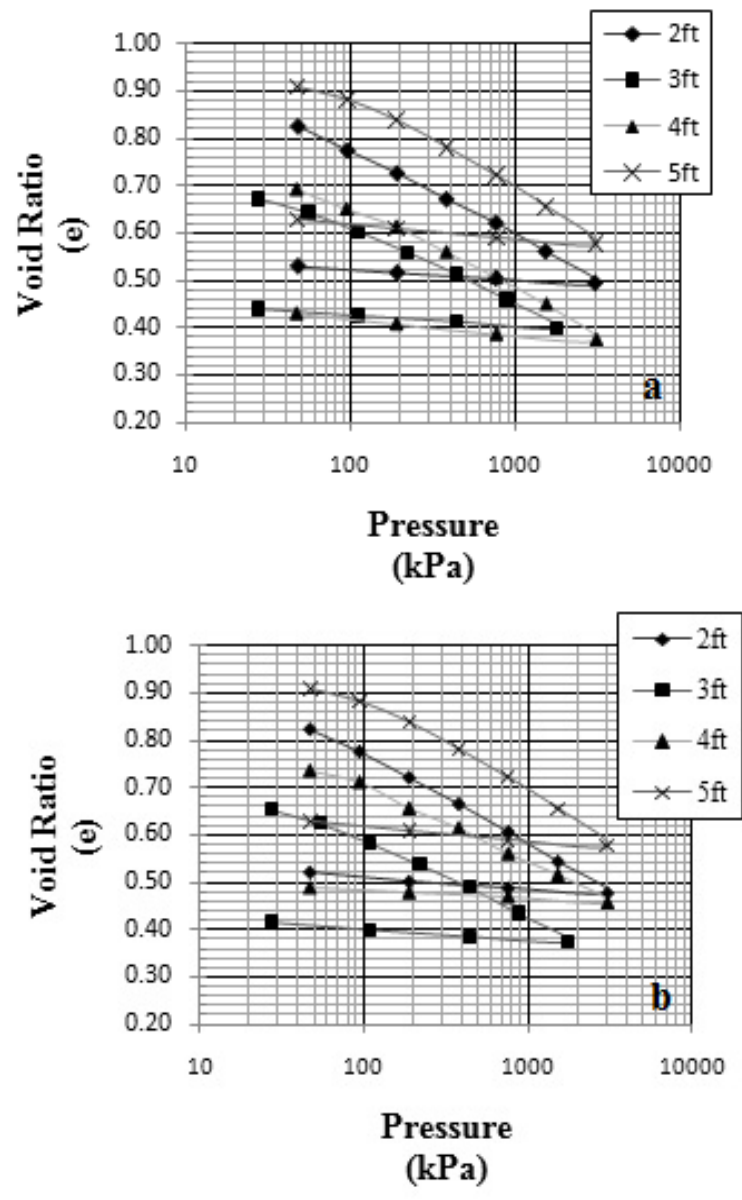

Fig. 3 (a \& b): Void Ratio- log Pressure Curves for Un-disturbed and Disturbed Samples
Fig. $3(\mathrm{a} \& \mathrm{~b})$ indicates the stress-strain behavior of the collected samples from KSK Campus, Lahore for disturbed and un-disturbed samples. Analysis shows that the void ratio for $4 \mathrm{ft}$ undisturbed sample range from 0.37 to 0.76 and for disturbed sample it is from 0.46 to 0.76 . Initial void ratio for the $5 \mathrm{ft}$ undisturbed sample is the highest value compared with other samples which 0.936.
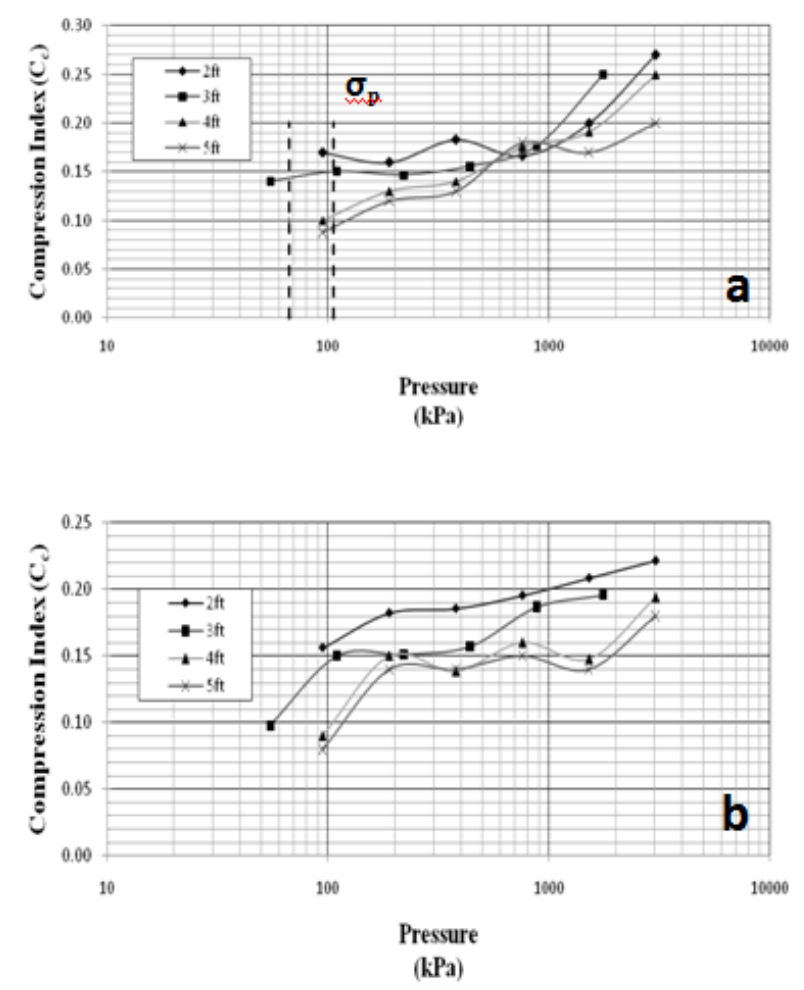

Fig. 4 (a \& b): Compression Index-log Pressure Relationship for Undisturbed and Disturbed Samples

Fig. 4 (a \& b) indicate the variation of compression index $\left(\mathrm{C}_{\mathrm{c}}\right)$ with $\log$ pressure for un-disturbed and disturbed samples. This shows that $\mathrm{C}_{\mathrm{c}}$ value generally increases with pressure increases. Similar findings have been reported by $[5,6,7,8]$. The $\mathrm{C}_{\mathrm{c}}$ values also decrease with depth indicating less potential of settlement with increase in depth.

Fig. 5 (a \& b) show the curves of coefficient of compressibility $\left(a_{v}\right)$ with pressure for un-disturbed and disturbed samples respectively. It can be seen that the value of $a_{v}$ decreases with increase in applied pressure. The values of $\mathrm{a}_{\mathrm{v}}$ are in scattered formation at initial pressures and converge closer to each other as applied pressure increases. This indicates that all soil samples have been compacted to a similar stiff structure and would behave in the same way under higher load. It is also observed that value of $a_{v}$ decreases with depth. 

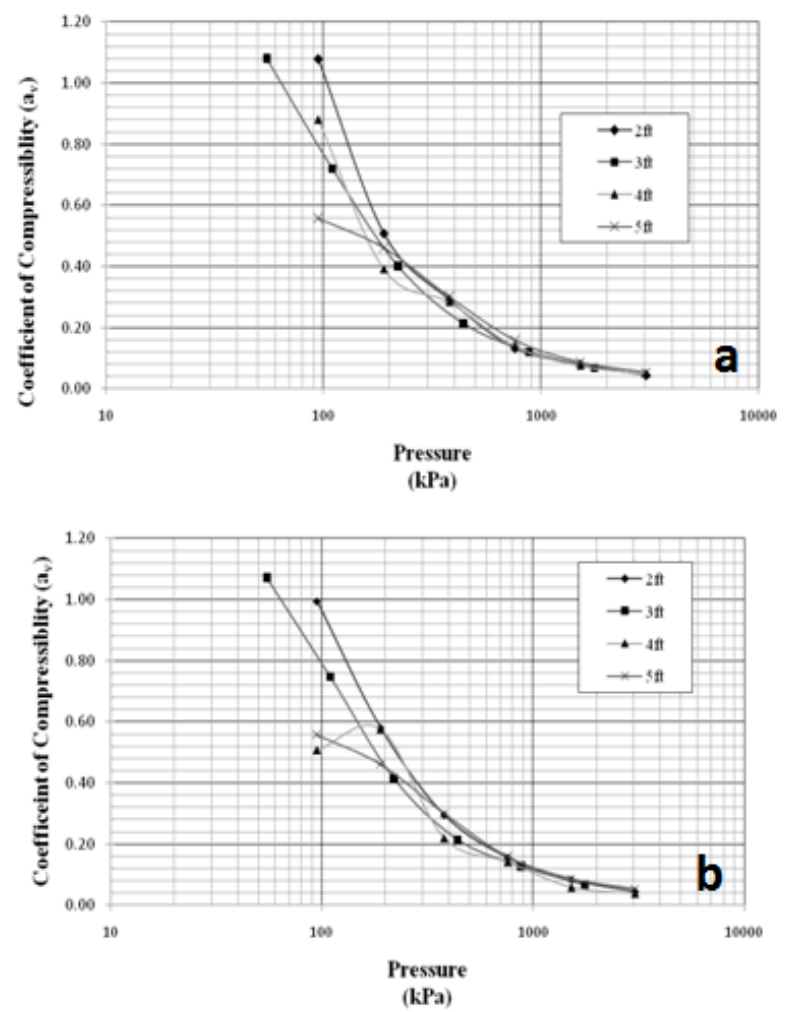

Fig. 5 (a \& b): The curves of coefficient of compressibility (av) with pressure.

Fig. 6 (a \& b) show the relationship of coefficient of volume compressibility with pressure $\left(\mathrm{m}_{\mathrm{v}}-\log \sigma_{\mathrm{v}}\right.$ curves) for un-disturbed and disturbed soil samples respectively. The discussion on the results is the same as stated for coefficient of compressibility above. Similar findings have been found by [9].
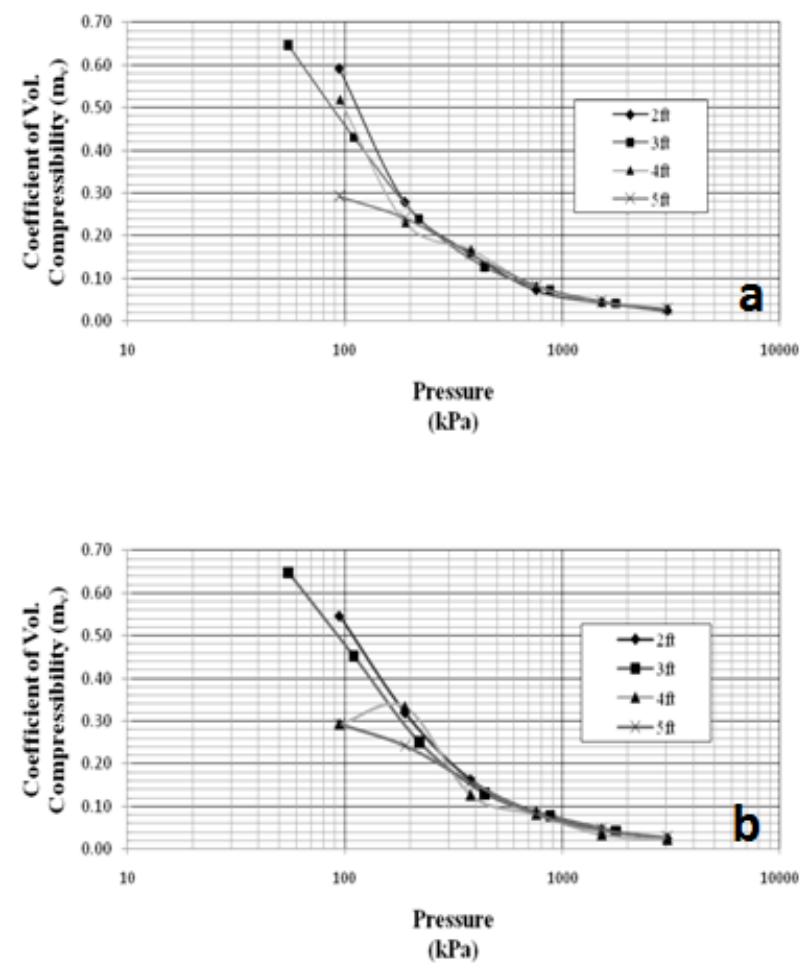

Fig. 6 (a \& b): The relationship of coefficient of volume compressibility with pressure

Fig. 7 ( $a \& b)$ indicate the variation of the coefficient of primary consolidation with pressure on log scale for undisturbed and disturbed samples. For un-disturbed samples it is seen that the values of $\mathrm{C}_{\mathrm{v}}$ decreases with increase in applied pressure and tends to be more or less constant at higher pressure.The values of $\mathrm{C}_{\alpha}$ for undisturbed and disturbed soil samples are plotted against pressure in Fig. 8 (a \& b). No definite conclusions can be drawn about the variation of $\mathrm{C}_{\alpha}$ with depth, however, the values of $\mathrm{C}_{\alpha}$ tend to increase and decrease with increase in pressure. Similar results have been reported by $[10,7,8]$.
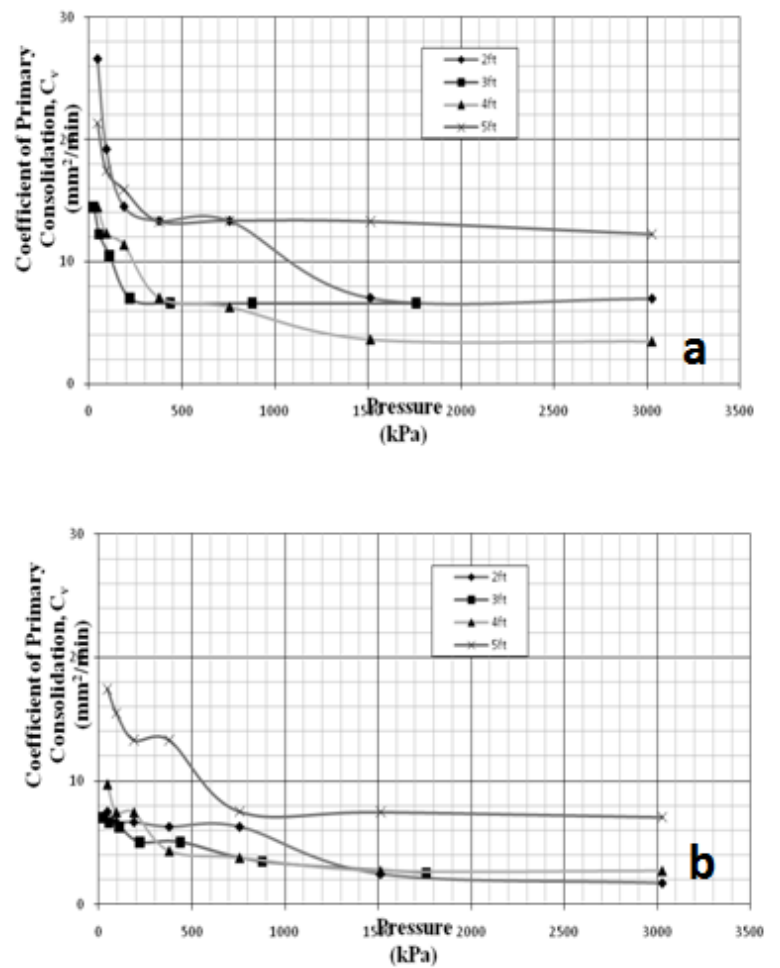

Fig. 7 (a \& b): Variation of the coefficient of primary consolidation with pressure on log scale
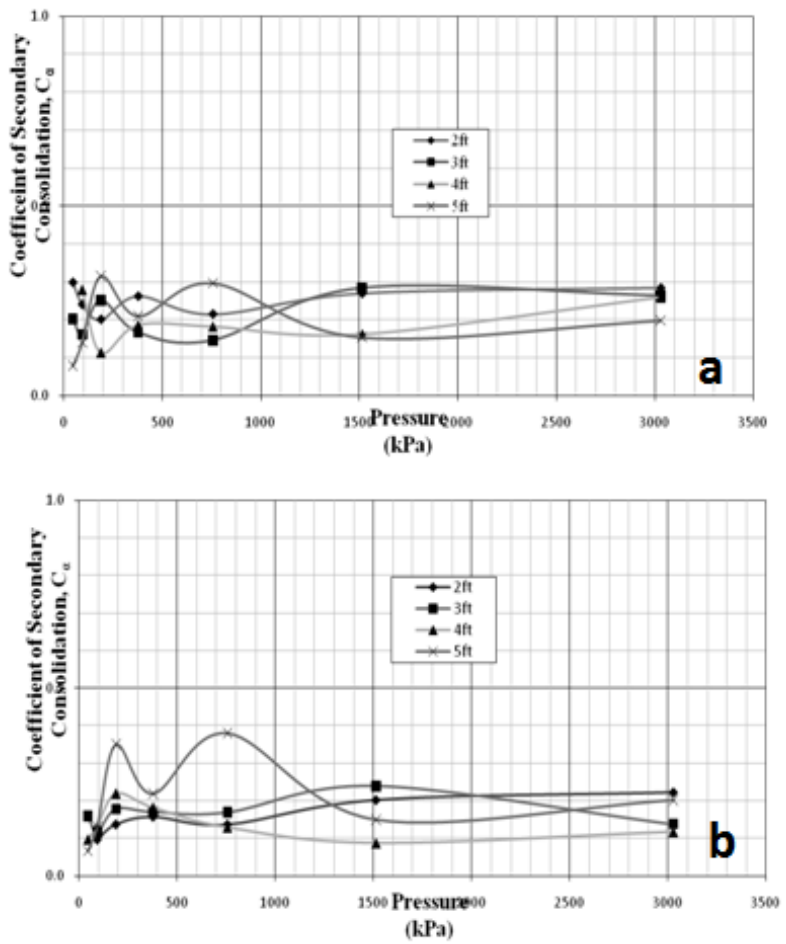

Fig. 8 (a \& b): The relationship between Coefficient of Secondary Consolidation with Pressure for Un-disturbed and Disturbed Samples 


\section{Conclusions}

On the basis of above data and its interpretation, the following conclusions are drawn;

1) The soil of the study area is classified as silty clay (CL-ML) up to $5 \mathrm{ft}$ depth with $3 \%$ to $7 \%$ sand. The natural moisture content to $4 \mathrm{ft}$ depth is very low and becomes $16 \%$ at $5 \mathrm{ft}$ and below.

2) The plastic limit of all the samples varies from 20 to 23 and the liquidity index shows that soil is in semisolid or solid state. Void ratio varies from 0.70 to 0.96 for undisturbed samples and 0.60 to 0.90 for disturbed samples.

3) The values of Cc have no definite trend with pressure, however it decreases with depth. For pressure range of $100 \mathrm{kPa}$ to $200 \mathrm{kPa}$, the values of $\mathrm{C}_{\mathrm{c}}$ vary between 0.07 to 0.18 respectively.

4) The values of $a_{v}$ and $m_{v}$ decrease with increase in applied pressure and depth. They are in scattered formation at initial pressure and converge closer to each other as applied pressure increases. For pressure range of $100 \mathrm{kPa}$ to $200 \mathrm{kPa}$, the values of $\mathrm{m}_{\mathrm{v}}$ vary between 0.23 to 0.65 and $a_{v}$ vary between 0.39 to 1.08 respectively.

5) The coefficient of primary consolidation $\mathrm{C}_{\mathrm{v}}$, decreases with increase in applied pressure and tends to be more or less constant at higher pressures. Also, the values of $\mathrm{C}_{\mathrm{v}}$ decreases with depth. The values of primary consolidation, $\mathrm{C}_{\mathrm{v}}$ varies between 1.71 to 26.62 .

6) The coefficient of secondary consolidation $\mathrm{C}_{\alpha}$, first increases with increase in applied pressure and tends to be more or less constant at higher pressures. No definite conclusion can be drawn about the variation of $\mathrm{C}_{\alpha}$ with depth.

\section{ACKNOWLEDGEMENT}

Authors pay special thanks to Prof. Dr. Aziz Akbar of Civil Engineering Department, UET, Lahore for his technical guidance and practical support. The services rendered by M. Shoaib are particularly appreciated for his contributions.

\section{REFERENCES}

[1] E. A. M. Osman, Research paper on New Reinforced Earth Mat foundation over Soft Clay, Dept. of Civil Engineering, Faculty of Engineering, University of Minia, Minia, Egypt. 2006.

[2] ASTM Standards D2435-96, Standard Test Method for OneDimensional Consolidation Properties of Soils, American Society for Testing and Materials 100, Barr Harbor Dr., West Conshohocken, PA 19428. 1996.

[3] Geotechnical and Transportation Engineering Division, Civil Engineering Department (GTED -2006), Geotechnical Investigation Report for Development of Kala Shah Kaku Campus of U.E.T., Lahore, Pakistan.

[4] A. Cassagrande and R. E. Fadum, "Note on Soil Testing for Engineering Purposes," Soil Mechanics Series Graduate School of Engineering, Harvard University, Cambridge, Mass. no. 5, 1940.

[5] D. T. Bergado, A. S. Enriquez, C. L. Sampaco, M. C. Alafaro, and A. S. Balasubramaniam, Inverse Analysis of Geotechnic Parameters on Improved Soft Bangkok Clay. 1992.

[6] S. Reinmanorom, One Dimensional Characteristics of Soft Nong Ngoo Hao Clay, M. Eng. Thesis no. 703, 1974.

[7] A. S. Teves and Z. C. Moh, "Compressibility of Soft and Medium Bangkok Clay," Research Report no. 4, 1968.

[8] A. Thumaprudti, One Dimensional Characteristics of Weathered Nong Ngoo Hao Clay, M. Eng. Thesis, no. 705, 1974.

[9] W. L. Sing, R. Hashim, and F. H. Ali, "Engineering Behavior of Stabilized Peat soil," European Journal of Scientific Research ISSN $1450-216 X$ vol. 21 no. 4 , pp. 581 to $591,2008$.

[10] B. Nanegrungsunk, Consolidation Characteristics of Pathumwan Clay, M. Eng. Thesis, no. 900, 1976. 